\title{
Usefulness of Rotational Thromboelastometry as a Mortality Predictor of Hyperfibrinolysis in Patients with Severe Trauma
}

\author{
Ji Soo Kim", Il Jae Wang ${ }^{1}$, Seok Ran Yeom ${ }^{1}$, Suck Ju Cho', Jae Hun Kim², June Pill Seok², Seong Hwa Lee', \\ Byung Gwan Bae', Mun Ki Min ${ }^{3}$
}

${ }^{1}$ Department of Emergency Medicine, Pusan National University Hospital, Busan; ${ }^{2}$ Department of Trauma Surgery, Pusan National University Hospital, Busan; ${ }^{3}$ Department of Emergency Medicine, Pusan National University Yangsan Hospital, Yangsan, Korea

Background: Hemorrhage is the major cause of traumatic death and the leading cause of preventable death. Hyperfibrinolysis is associated with trauma severity. Viscoelastic hemostatic assays show complete clot formation dynamics. The present study was designed to identify the relationship between hyperfibrinolysis and mortality, metabolic acidosis, and coagulopathy in patients with trauma.

Methods: Patients with severe trauma (injury severity score [ISS] of 15 or higher) who were assessed using rotational thromboelastometry (ROTEM) were included in the present study from January 2017 to December 2017. Variables were obtained from the Korea Trauma Database or the medical charts of the patients. To identify whether hyperfibrinolysis is an independent predictor of mortality, univariate and multivariate Cox regression analyses were performed.

Results: During the 1-year study period, 190 patients were enrolled. In total, 21 (11.1\%) had hyperfibrinolysis according to the ROTEM analysis and $46(24.2 \%)$ died. Patients with hyperfibrinolysis had a higher ISS $(P=0.014)$ and mortality rate $(P<0.001)$ than did those without hyperfibrinolysis. In multivariate Cox analysis, hyperfibrinolysis (hazard ratio [HR], 4.960; 95\% confidence interval [Cl], 2.447 to 10.053), age ( $\mathrm{HR}, 1.033 ; 95 \% \mathrm{Cl}, 1.013$ to 1.055$)$, lactic acid level $(\mathrm{HR}, 1.085 ; 95 \% \mathrm{Cl}, 1.003$ to 1.173), and ISS ( $\mathrm{HR}, 1.037 ; 95 \% \mathrm{Cl}, 1.004$ to 1.071$)$ were independent predictors of mortality.

Conclusions: Hyperfibrinolysis is associated with increased mortality, worse metabolic acidosis, and severe coagulopathy and is an independent predictor of mortality in patients with trauma.

Key Words: coagulopathy; fibrinolysis; hemorrhage; thromboelastometry; trauma

\section{INTRODUCTION}

Trauma is the most common cause of death in individuals aged younger than 40 years [1], and bleeding is the major cause of traumatic death and is the leading cause of preventable death [2]. Some patients with traumatic bleeding develop coagulopathy, and those with coagulopathy generally have a higher mortality rate (25\%) [3]. The mechanism of trauma-induced coagulopathy is multifactorial and includes hemodilution, hypothermia, platelet (Plt) dysfunction, coagulation factor deficiency, metabolic acidosis, and hyperfibrinolysis $[4,5]$.

\section{Original Article}

Received: May 29, 2018

Revised: July 2, 2018

Accepted: August 17, 2018

Corresponding author II Jae Wang

Department of Emergency Medicine, Pusan National University Hospital, 179 Gudeok-ro, Seo-gu, Busan 49241, Korea

Tel: +82-51-240-7503

Fax: +82-51-253-6472

E-mail:jrmr9933@gmail.com

Copyright (๑) 2018 The Korean Society of Critical Care Medicine

This is an Open Access article distributed under the terms of Creative Attributions Non-Commercial License (http://

creativecommons.org/li-censes/by-nc/4.0/ which permits unrestricted noncommercial use, distribution, and reproduction in any medium, provided the original work is properly cited. 
Hyperfibrinolysis is a pathologic condition in which the rate of fibrinolysis is higher than that of fibrin formation [6]. This condition is associated with trauma severity, which increases mortality $[7,8]$. The degree of fibrinolysis is difficult to measure, and the diagnosis of hyperfibrinolysis within a clinically significant period of time is even more challenging to complete. Standard laboratory coagulation tests (e.g., prothrombin time [PT], partial thromboplastin time [PTT], and Plt count) cannot be used to measure fibrinolysis [9]. Euglobulin lysis time (ELT) is not clinically useful in individuals with trauma due to its prolonged analysis time, absence of plasma inhibitor, and lack of capability in evaluating the response to antifibrinolytic agents $[6,10]$. Recently, studies on the diagnosis of hyperfibrinolysis using viscoelastic hemostatic assays (VHAs) (e.g., rotational thromboelastometry [ROTEM] and thromboelastography are increasing in number [11-13]. VHAs show the complete clot formation dynamics (i.e., initiation, amplification, strength, and fibrinolysis) in a manner that is faster than laboratory coagulation tests $[14,15]$.

However, to our knowledge, investigations on the use of VHAs in patients with trauma in Korea have not yet been conducted. Moreover, research on the association between hyperfibrinolysis and clinical outcomes remains limited. Thus, the present study aimed to identify the relationship between hyperfibrinolysis and mortality, metabolic acidosis, and coagulopathy in patients with trauma and to determine whether hyperfibrinolysis is an independent predictor of death in these individuals.

\section{MATERIALS AND METHODS}

This was a retrospective observational study conducted at an authorized regional trauma center. The Institutional Review Board of Pusan National University Hospital approved the study design (IRB No. 1805-019-067). Patients with trauma (injury severity score [ISS] of 15 or higher) who were included in the analysis that used ROTEM were included in the present study between January 2017 and December 2017. Patients aged $\leq 15$ years; those who arrived at the hospital at a point more than 12 hours following trauma; and those with a history of burns, hanging, or drowning were excluded.

The following variables were obtained from the Korea Trauma Database: age, sex, systolic blood pressure at presentation, Glasgow coma scale (GCS), ISS, revised trauma score (RTS), mortality, and transfusion. We collected laboratory data from the electronic medical charts of the included patients. Information about hemoglobin ( $\mathrm{Hb}$ ) level, PT (international nor-

\section{KEYMESSAGES}

- Hyperfibrinolysis is associated with increased mortality, worse metabolic acidosis, and severe coagulopathy and is an independent predictor of mortality in patients with trauma.

- Investigations on the use of viscoelastic hemostatic assays in patients with trauma in Korea have not yet been conducted.

malized ratio [INR]), activated PTT (aPTT), Plt count, fibrinogen level, base excess, and lactic acid level was gathered. Severe trauma was defined as an ISS $\geq 15$, and massive transfusion was defined as a transfusion that involved $\geq 10 \mathrm{U}$ of packed red blood cells within the first 24 hours of admission $[16,17]$.

ROTEM provides information from clot initiation to fibrinolysis in real time. During use of the ROTEM device, blood is placed inside a cup and the plastic pin is vertically immersed in the cup. The pin subsequently rotates to the left and right. The movement of the pin is not restricted until the coagulation is initiated. As soon as blood clot formation begins, the movement of the pin is restricted. As the clot firmness increases, the movement of the pin becomes more restrictive. The movement of the pin is inversely proportional to the clot firmness, and this is shown in a graphical display. The ROTEM device is a four-channel system that is capable of simultaneously performing four tests. Activators or inhibitors are added to the blood to clearly and rapidly evaluate coagulation status. The basic ROTEM tests (INTEM and EXTEM) add ellagic acid and tissue factor, respectively, and coagulation is activated via the intrinsic and extrinsic pathways. In FIBTEM, cytochalasin D was added to block Plts. Therefore, in FIBTEM, the clot depends only on fibrinogen. In APTEM, antifibrinolytic agent (aprotinin) is added to inhibit fibrinolysis. APTEM is usually used to confirm hyperfibrinolysis. The following ROTEM parameters were included in this study: (1) clotting time, referring to initiation of clotting; (2) clot formation time (CFT), referring to time from clot initiation to a clot firmness of $20 \mathrm{~mm}$; (3) maximum clot firmness (MCF), referring to maximum clot strength; and (4) maximum lysis (ML), referring to the reduction of clot firmness after achieving MCF (Figure 1). The ROTEM reference values were based on previous research by Lang et al. [18]. Blood samples for ROTEM test were obtained at initial presentation to the emergency department. Hyperfibrinolysis was diagnosed when the EXTEM ML was $>15$ and the APTEM ML was normal (Figure 2) $[6,10]$.

Categorical variables were presented as frequencies and 


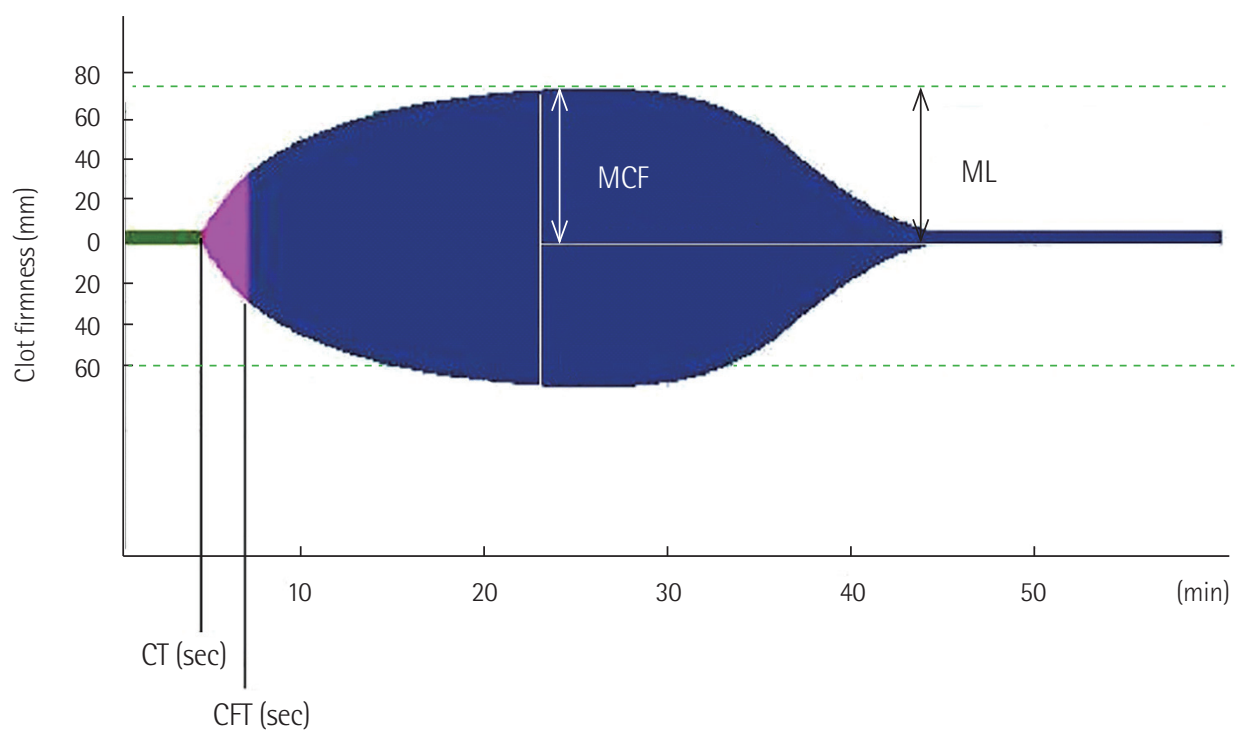

Figure 1. The parameters of rotational thromboelastometry. (1) Clotting time (CT): initiation of clotting; (2) clot formation time (CFT): time from clot initiation to a clot firmness of $20 \mathrm{~mm}$; (3) maximum clot firmness (MCF): maximum clot strength; and (4) maximum lysis (ML): reduction of clot firmness after achieving MCF.
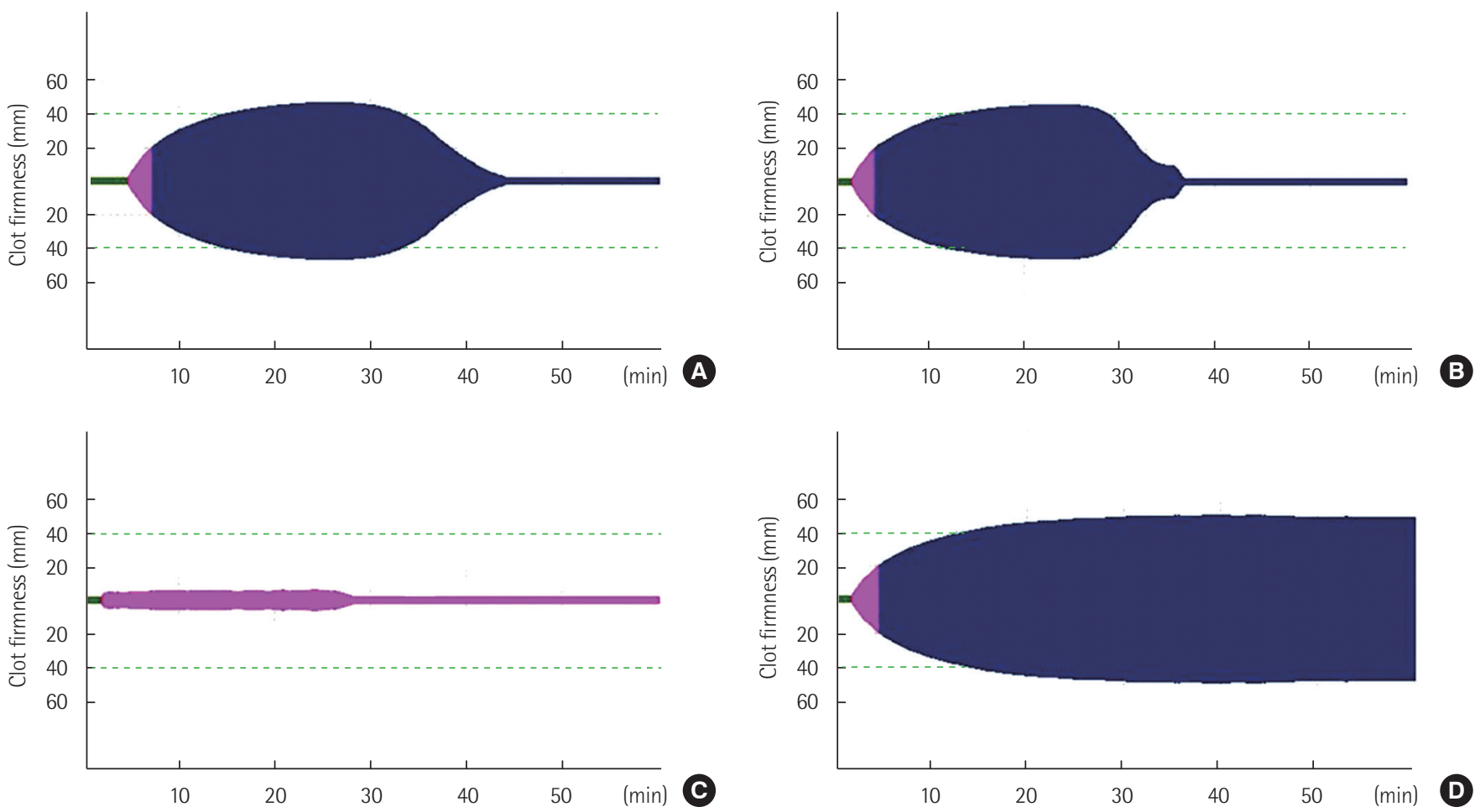

Figure 2. Hyperfibrinolysis in (A) INTEM, (B) EXTEM, and (C) FIBTEM. (D) The APTEM shows stable clot formation.

percentages, while continuous variables were presented as means and standard deviations or medians and interquartile ranges according to normality. For categorical variables, Fisher exact test was used. For continuous variables, we compared variables by use of a t-test or Wilcoxon rank-sum test according to normality. Survival curves were obtained using the Kaplan-Meier method, and a log-rank test was performed to assess the hospital mortality rate of the hyperfibrinolysis and 
non-hyperfibrinolysis groups. To identify whether hyperfibrinolysis is an independent predictor of mortality, univariate

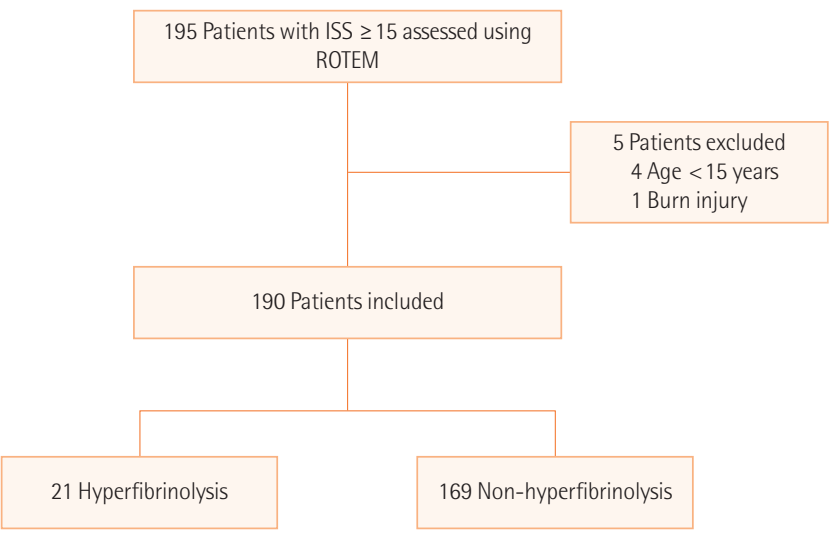

Figure 3. Patient flow. ISS: injury severity score; ROTEM: rotational thromboelastometry. and multivariate Cox regression analyses were performed. A Cox regression model was used to obtain hazard ratio (HRs) and $95 \%$ confidence intervals (CIs). All data analyses were performed using R 3.3.2 (The R Foundation, Vienna, Austria). Survival analysis was performed using the survival package, and comparisons between the two groups were performed using the tableone package. The $\mathrm{P}<0.05$ was considered statistically significant.

\section{RESULTS}

During the 1-year study period, 190 patients were enrolled (Figure 3). The demographic information of the participants is summarized in Table 1. Of the study participants, 148 (77.9\%) were male, and $183(96.3 \%)$ had blunt trauma. The number of traffic accidents was $110(57.9 \%)$ and that of falls was 21 (11.1\%).

Table 1. Patient demographics and baseline characteristics

\begin{tabular}{|c|c|c|c|c|}
\hline Variable & $\begin{array}{l}\text { All patients } \\
(n=190)\end{array}$ & $\begin{array}{l}\text { Hyperfibrinolysis } \\
\qquad(n=21)\end{array}$ & $\begin{array}{l}\text { Non-hyperfibrinolysis } \\
\qquad(\mathrm{n}=169)\end{array}$ & P-value \\
\hline Sex & & & & 0.050 \\
\hline Male & $148(77.9)$ & 20 (95.2) & $128(75.7)$ & \\
\hline Female & $42(22.1)$ & $1(4.8)$ & $41(24.3)$ & \\
\hline Age (yr) & $53.87 \pm 17.54$ & $51.14 \pm 17.59$ & $54.21 \pm 17.55$ & 0.458 \\
\hline Injury mechanism & & & & 0.393 \\
\hline Traffic accident & $110(57.9)$ & $11(52.4)$ & 99 (58.6) & \\
\hline Fall down & $21(11.1)$ & $1(4.8)$ & $20(11.8)$ & \\
\hline Penetrating Injury & $7(3.7)$ & 0 & $7(4.1)$ & \\
\hline Others & $52(27.4)$ & $9(42.9)$ & $43(25.4)$ & \\
\hline Systolic blood pressure (mmHg) & $95.21 \pm 43.00$ & $61.67 \pm 56.54$ & $99.37 \pm 39.26$ & 0.007 \\
\hline Pulse rate $(\mathrm{mmHg})$ & $97.44 \pm 30.13$ & $89.10 \pm 44.66$ & $98.47 \pm 27.83$ & 0.357 \\
\hline Respiratory rate (mmHg) & $20.27 \pm 8.07$ & $17.90 \pm 11.82$ & $20.57 \pm 7.47$ & 0.324 \\
\hline GCS & $10.51 \pm 4.78$ & $5.38 \pm 3.19$ & $11.14 \pm 4.56$ & $<0.001$ \\
\hline RTS & $9.59 \pm 2.87$ & $5.86 \pm 3.64$ & $10.05 \pm 2.39$ & $<0.001$ \\
\hline Transfusion & & & & 0.028 \\
\hline No & $31(16.3)$ & 0 & 31 (18.3) & \\
\hline Yes & 159 (83.7) & $21(100.0)$ & $138(81.7)$ & \\
\hline Massive transfusion & & & & 0.001 \\
\hline No & $143(75.3)$ & $9(42.9)$ & 134 (79.3) & \\
\hline Yes & $47(24.7)$ & $12(57.1)$ & $35(20.7)$ & \\
\hline ISS & $29.86 \pm 9.82$ & $34.48 \pm 8.39$ & $29.29 \pm 9.85$ & 0.014 \\
\hline Death & & & & $<0.001$ \\
\hline No & $144(75.8)$ & $4(19.0)$ & $140(82.8)$ & \\
\hline Yes & $46(24.2)$ & $17(81.0)$ & $29(17.2)$ & \\
\hline
\end{tabular}

Values are presented as number (\%) or mean \pm standard deviation.

GCS: Glasgow coma scale; RTS: revised trauma score; ISS: injury severity score. 
The mean age of the participants was $53 \pm 17.54$ years, the mean ISS was $29 \pm 9.82$, the admission RTS was $9.59 \pm 2.87$, and the admission GCS was $10.51 \pm 4.78$.

We divided the participants into two groups according to the presence of hyperfibrinolysis. In total, 21 patients (11.1\%) were identified as having hyperfibrinolysis in the analysis that used ROTEM, and 46 patients (24.2\%) died. Patients with hyperfibrinolysis had a higher ISS (34.48 \pm 8.39 vs. $29.29 \pm 9.85$, $\mathrm{P}=0.014)$, higher transfusion rate ( $100 \%$ vs. $81.7 \%, \mathrm{P}=0.028)$, lower admission systolic blood pressure (61.6 \pm 56.5 vs. $99.3 \pm$ $39.2 \mathrm{mmHg}, \mathrm{P}=0.007)$, and lower GCS (5.38 \pm 3.19 vs. $11.14 \pm$ 4.56, $\mathrm{P}<0.001)$ than did those without hyperfibrinolysis. In the laboratory analysis, the lactic acid level $(\mathrm{P}<0.001)$ and PT INR $(\mathrm{P}<0.001)$ of the hyperfibrinolysis group were significantly higher than those of the non-hyperfibrinolysis group (Table 2). With regard to ROTEM parameters, the EXTEM clotting time $(\mathrm{P}<0.001)$ and EXTEM CFT $(\mathrm{P}<0.001)$ of the hyperfibrinolysis group were significantly prolonged, whereas the EXTEM MCF $(\mathrm{P}<0.001)$ of the hyperfibrinolysis group was lower. Hyperfibrinolysis was associated with worse metabolic acidosis and severe coagulopathy. The Kaplan-Meier survival curves showed that the mortality rate of patients with hyperfibrinolysis was higher than that of those without hyperfibrinolysis (logrank test, $\mathrm{P}<0.0001)$. Moreover, patients with hyperfibrinolysis died earlier than did those without hyperfibrinolysis. The 1-day survival rate of the hyperfibrinolysis group was $50 \%$, and that of the non-hyperfibrinolysis group was 93.4\% (Figure 4).

To investigate independent predictors of mortality, univariate and multivariate Cox analyses were performed (Table 3). Univariate analysis revealed that hyperfibrinolysis, age, ISS, PT INR, and lactic acid level were significantly associated with mortality. In the multivariate analysis, hyperfibrinolysis (HR, 4.960; 95\% CI, 2.447 to 10.053), age (HR, 1.033; 95\% CI, 1.013 to 1.055$)$, lactic acid level (HR, 1.085; 95\% CI, 1.003 to 1.173 ), and ISS (HR, 1.037; 95\% CI, 1.004 to 1.071 ) were considered to be independent predictors of mortality (Table 4 ).

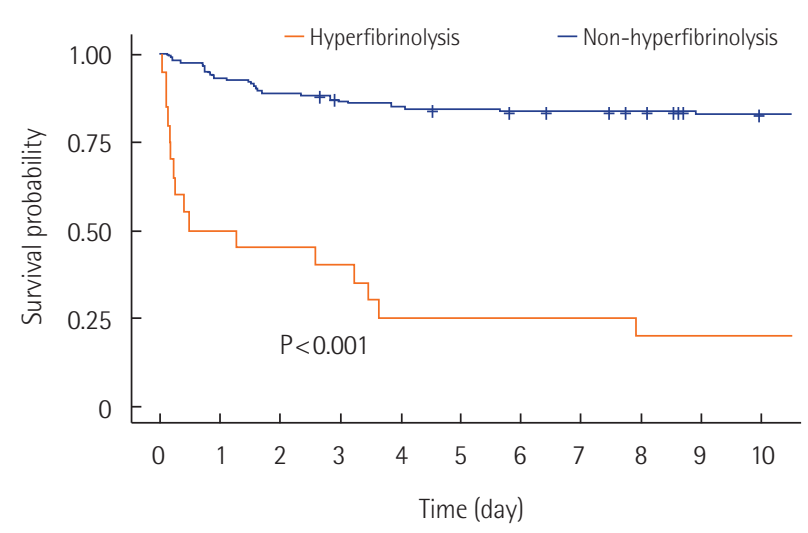

Figure 4. Kaplan-Meier survival curves showing mortality differences between patients with and without hyperfibrinolysis. $\mathrm{P}<0.001$ by log-rank test.

Table 2. Laboratory values and ROTEM parameters by hyperfibrinolysis

\begin{tabular}{lcccc}
\hline Variable & $\begin{array}{c}\text { All patients } \\
(\mathrm{n}=190)\end{array}$ & $\begin{array}{c}\text { Hyperfibrinolysis } \\
(\mathrm{n}=21)\end{array}$ & $\begin{array}{c}\text { Non-hyperfibrinolysis } \\
(\mathrm{n}=169)\end{array}$ & P-value \\
\hline PT INR & $1.14(1.02-1.31)$ & $1.43(1.27-1.76)$ & $1.11(1.00-1.23)$ & $<0.001$ \\
aPTT & $30.35(26.40-38.72)$ & $54.20(39.30-72.70)$ & $29.70(26.35-35.25)$ & $<0.001$ \\
Hb & $12.00 \pm 2.68$ & $11.18 \pm 4.07$ & $12.11 \pm 2.45$ & 0.317 \\
Platelet & $205.48 \pm 76.74$ & $166.62 \pm 78.96$ & $210.31 \pm 75.31$ & 0.024 \\
Fibrinogen & $174.90(129.10-221.00)$ & $126.40(80.20-173.50)$ & $179.40(137.60-223.10)$ & 0.003 \\
pH & $7.36 \pm 0.08$ & $7.30 \pm 0.09$ & $7.37 \pm 0.08$ & 0.025 \\
Lactic acid & $5.00 \pm 3.85$ & $9.71 \pm 4.33$ & $4.41 \pm 3.35$ & $<0.001$ \\
EXTEM CT & $58.00(52.00-74.00)$ & $101.00(66.00-139.00)$ & $57.00(51.00-68.00)$ & $<0.001$ \\
EXTEM CFT & $104.50(75.00-134.00)$ & $157.00(108.00-233.00)$ & $99.00(75.00-128.00)$ & $<0.001$ \\
EXTEM MCF & $54.55 \pm 13.19$ & $39.81 \pm 15.46$ & $56.38 \pm 11.70$ & $<0.001$ \\
INTEM CT & $181.00(145.00-222.75)$ & $243.00(226.00-272.00)$ & $172.00(143.00-210.00)$ & $<0.001$ \\
INTEM CF & $97.00(72.25-147.75)$ & $149.00(100.00-264.00)$ & $94.00(71.00-133.00)$ & 0.005 \\
INTEM MCF & $54.46 \pm 13.22$ & $38.86 \pm 15.83$ & $56.40 \pm 11.52$ & $<0.001$ \\
\hline
\end{tabular}

Values are presented as median (interquartile range) or mean \pm standard deviation.

ROTEM: rotational thromboelastometry; PT: prothrombin time; INR: international normalized ratio; aPT: activated partial thromboplastin time; CT: clotting time; CF: clot formation time; MCF: maximum clot firmness. 
Table 3. Univariate analysis of risk factor for mortality in patients with severe trauma

\begin{tabular}{lccc}
\hline Variable & Hazard ratio & $95 \%$ Cl & P-value \\
\hline Age & 1.023 & $1.005-1.042$ & 0.013 \\
Male & 2.390 & $0.944-6.048$ & 0.066 \\
Injury mechanism & & & \\
$\quad$ Traffic accident & 1 & Reference & - \\
$\quad$ Fall down & 0.532 & $0.162-1.749$ & 0.298 \\
$\quad$ Others & 1.063 & $0.568-1.991$ & 0.849 \\
Systolic blood pressure & 0.989 & $0.981-0.996$ & 0.004 \\
GCS & 0.756 & $0.698-0.820$ & $<0.001$ \\
RTS & 0.768 & $0.715-0.825$ & $<0.001$ \\
ISS & 1.061 & $1.032-1.092$ & 0.014 \\
PT INR & 1.309 & $1.166-1.469$ & $<0.001$ \\
aPTT & 1.020 & $1.013-1.027$ & $<0.001$ \\
Platelet & 0.995 & $0.991-0.999$ & 0.024 \\
Lactic acid & 1.145 & $1.084-1.211$ & $<0.001$ \\
Hyperfibrinolysis & 8.309 & $4.502-15.336$ & $<0.001$ \\
\hline
\end{tabular}

$\mathrm{Cl}$ : confidence interval; GCS: Glasgow coma scale; RTS: revised trauma score; ISS: injury severity score; PT: prothrombin time; INR: international normalized ratio; aPT: activated partial thromboplastin time.

\section{DISCUSSION}

The primary findings of the present study were as follows. Hyperfibrinolysis was associated with increased mortality, worse metabolic acidosis, and poor coagulopathy in patients with severe trauma and was an independent predictor of mortality in patients with trauma. Age, lactic acid level, and ISS were also considered to be independent predictors.

Hyperfibrinolysis is a major component of acute traumatic coagulopathy, and its presence suggests a poor prognosis. However, the diagnosis of hyperfibrinolysis is challenging, and its diagnosis using the ROTEM has not been standardized. Levrat et al. [19] assessed 23 patients with trauma who underwent the ELT test. Patients with an ELT of $<90$ minutes were diagnosed with hyperfibrinolysis, with a total of five patients diagnosed with hyperfibrinolysis. When matched with the ROTEM results, an EXTEM MCF of $<18 \mathrm{~mm}$ showed $100 \%$ sensitivity and specificity. Kutcher et al. [20] diagnosed patients with hyperfibrinolysis if they had an EXTEM ML and APTEM ML $>10$. In total, 115 patients were critically injured, and 20 patients were diagnosed with hyperfibrinolysis. In 2009, Schöchl et al. [8] described hyperfibrinolysis as hyperfibrinolytic lysis present in the EXTEM (ML > 15) but not in the APTEM; subsequently, most studies have used this same criteri-
Table 4. Multivariate adjusted hazard ratio for mortality in patients with severe trauma

\begin{tabular}{lccc}
\hline Variable & Hazard ratio & $95 \% \mathrm{Cl}$ & P-value \\
\hline Hyperfibrinolysis & 4.960 & $2.447-10.053$ & $<0.001$ \\
Male & 1.778 & $0.673-4.694$ & 0.246 \\
Age & 1.033 & $1.013-1.055$ & 0.001 \\
Accident mechanism & & & \\
$\quad$ Traffic accident & 1.000 & Reference & - \\
Fall down & 0.914 & $0.268-3.118$ & 0.886 \\
Others & 1.094 & $0.545-2.196$ & 0.800 \\
PT INR & 1.057 & $0.901-1.241$ & 0.495 \\
Lactic acid & 1.085 & $1.003-1.173$ & 0.042 \\
ISS & 1.037 & $1.004-1.071$ & 0.026 \\
\hline
\end{tabular}

$\mathrm{Cl}$ : confidence interval; PT: prothrombin time; INR: international normalized ratio; ISS: injury severity score.

on $[7,10,21,22]$. Currently, it is a widely accepted hyperfibrinolysis diagnosis criterion [6], and we used this criterion in our study.

In this study, the mortality rate of patients with hyperfibrinolysis was $81 \%$, and those with hyperfibrinolysis typically died earlier. More than $64 \%$ of deaths from hyperfibrinolysis occurred within 4 days. Our results are similar to those reported in a study by Theusinger et al. [7]. Out of 552 patients with and without trauma, 13 had hyperfibrinolysis due to trauma, and 24 developed hyperfibrinolysis due to nontrauma causes. The 30-day mortality rate (77\%) of patients with hyperfibrinolysis due to trauma was approximately twice that $(41 \%)$ of patients with hyperfibrinolysis due to nontrauma causes. All deaths from hyperfibrinolysis due to trauma occurred within 4 days.

In our study, the univariate Cox analysis showed that the proportion of patients with hyperfibrinolysis who died was significantly higher. After adjusting for age, sex, injury mechanism, ISS, coagulation state (PT INR), and shock state (lactic acid level), hyperfibrinolysis was considered as an independent predictor of mortality. Of the other studies that considered hyperfibrinolysis as an independent predictor of mortality, Ives et al. [23] analyzed 118 patients with trauma and diagnosed 13 with hyperfibrinolysis. These authors identified hyperfibrinolysis as a strong independent predictor of mortality. Moreover, age, ISS, and lactic acid level were found to be independent predictors of mortality in patients with trauma.

ROTEM is useful in identifying patients with hyperfibrinolysis due to severe trauma in real time. Although, Cochrane's systematic review suggests that now VHA should only be used for research purposes in trauma patients [24]. Still, many stud- 
ies have identified the usefulness of VHA in the trauma setting [25-29]. To the best of our knowledge, there is no study published that has involved VHA use in patients with severe trauma in Korea. Therefore, this study is significant because it showed the first application of VHAs in patients with trauma in Korea.

The present study had several limitations. First, this was a retrospective study, so selection bias could have been present. Second, the study was conducted in a single center; thus, the results could not be generalized. Third, the number of patients with hyperfibrinolysis is small, and the statistical power is limited. Fourth, tranexamic acid is an antifibrinolytic agent, which was widely studied in patients with trauma, and is considered an evidence-based treatment of hyperfibrinolysis in patients with trauma [2]. However, we did not investigate the association between the administration of tranexamic acid and mortality. Finally, we did not measure the fibrinolytic activity based on laboratory tests, such as ELT, plasmin-a2-antiplasmin, and plasminogen activator inhibitor-1.

In conclusion, hyperfibrinolysis is associated with increased mortality, worse metabolic acidosis, and severe coagulopathy. Moreover, it is an independent predictor of mortality in patients with trauma. Other independent predictors of mortality include ISS, lactic acid level, and age.

\section{CONFLICT OF INTEREST}

No potential conflict of interest relevant to this article was reported.

\section{ACKNOWLEDGMENTS}

This work was supported by Department of Biostatistics, Clinical Trial Center, Biomedical Research Institute, Pusan National University Hospital, Busan, Korea.

\section{ORCID}

Il Jae Wang https://orcid.org/0000-0003-2479-2359

\section{REFERENCES}

1. Cothren CC, Moore EE, Hedegaard HB, Meng K. Epidemiology of urban trauma deaths: a comprehensive reassessment 10 years later. World J Surg 2007;31:1507-11.

2. Ramirez RJ, Spinella PC, Bochicchio GV. Tranexamic acid update in trauma. Crit Care Clin 2017;33:85-99.
3. Brohi K, Singh J, Heron M, Coats T. Acute traumatic coagulopathy. J Trauma 2003;54:1127-30.

4. Davenport R. Pathogenesis of acute traumatic coagulopathy. Transfusion 2013;53 Suppl 1:23S-27S.

5. Cohen MJ, Call M, Nelson M, Calfee CS, Esmon CT, Brohi K, et al. Critical role of activated protein $\mathrm{C}$ in early coagulopathy and later organ failure, infection and death in trauma patients. Ann Surg 2012;255:379-85.

6. Gall LS, Brohi K, Davenport RA. Diagnosis and treatment of hyperfibrinolysis in trauma (a European Perspective). Semin Thromb Hemost 2017;43:224-34.

7. Theusinger OM, Wanner GA, Emmert MY, Billeter A, Eismon J, Seifert B, et al. Hyperfibrinolysis diagnosed by rotational thromboelastometry (ROTEM) is associated with higher mortality in patients with severe trauma. Anesth Analg 2011;113: 1003-12.

8. Schöchl H, Frietsch T, Pavelka M, Jámbor C. Hyperfibrinolysis after major trauma: differential diagnosis of lysis patterns and prognostic value of thrombelastometry. J Trauma 2009;67: 125-31.

9. Raza I, Davenport R, Rourke C, Platton S, Manson J, Spoors C, et al. The incidence and magnitude of fibrinolytic activation in trauma patients. J Thromb Haemost 2013;11:307-14.

10. Gall LS, Davenport RA. Fibrinolysis and antifibrinolytic treatment in the trauma patient. Curr Opin Anaesthesiol 2018;31: 227-33.

11. Gonzalez E, Moore EE, Moore HB. Management of traumainduced coagulopathy with thrombelastography. Crit Care Clin 2017;33:119-34.

12. Liras IN, Cotton BA, Cardenas JC, Harting MT. Prevalence and impact of admission hyperfibrinolysis in severely injured pediatric trauma patients. Surgery 2015;158:812-8.

13. Moore HB, Moore EE, Gonzalez E, Chapman MP, Chin TL, Silliman CC, et al. Hyperfibrinolysis, physiologic fibrinolysis, and fibrinolysis shutdown: the spectrum of postinjury fibrinolysis and relevance to antifibrinolytic therapy. J Trauma Acute Care Surg 2014;77:811-7.

14. Cardenas JC, Matijevic N, Baer LA, Holcomb JB, Cotton BA, Wade CE. Elevated tissue plasminogen activator and reduced plasminogen activator inhibitor promote hyperfibrinolysis in trauma patients. Shock 2014;41:514-21.

15. Carroll RC, Craft RM, Langdon RJ, Clanton CR, Snider CC, Wellons DD, et al. Early evaluation of acute traumatic coagulopathy by thrombelastography. Transl Res 2009;154:34-9.

16. Demetriades D, Martin M, Salim A, Rhee P, Brown C, Doucet J, et al. Relationship between American College of Surgeons trauma center designation and mortality in patients with se- 
vere trauma (injury severity score > 15). J Am Coll Surg 2006; 202:212-5

17. Leemann H, Lustenberger T, Talving P, Kobayashi L, Bukur M, Brenni M, et al. The role of rotation thromboelastometry in early prediction of massive transfusion. J Trauma 2010;69: 1403-8.

18. Lang T, Bauters A, Braun SL, Pötzsch B, von Pape KW, Kolde $\mathrm{HJ}$, et al. Multi-centre investigation on reference ranges for ROTEM thromboelastometry. Blood Coagul Fibrinolysis 2005; 16:301-10.

19. Levrat A, Gros A, Rugeri L, Inaba K, Floccard B, Negrier C, et al. Evaluation of rotation thrombelastography for the diagnosis of hyperfibrinolysis in trauma patients. Br J Anaesth 2008; 100:792-7.

20. Kutcher ME, Cripps MW, McCreery RC, Crane IM, Greenberg MD, Cachola LM, et al. Criteria for empiric treatment of hyperfibrinolysis after trauma. J Trauma Acute Care Surg 2012; 73:87-93.

21. Akay OM. The double hazard of bleeding and thrombosis in hemostasis from a clinical point of view: a global assessment by Rotational Thromboelastometry (ROTEM). Clin Appl Thromb Hemost 2018;24:850-8.

22. Gomez-Builes JC, Acuna SA, Nascimento B, Madotto F, Rizoli SB. Harmful or physiologic: diagnosing fibrinolysis shutdown in a trauma cohort with rotational thromboelastometry. Anesth Analg 2018 Apr 19 [Epub]. https://doi.org/10.1213/ANE.000 0000000003341

23. Ives C, Inaba K, Branco BC, Okoye O, Schochl H, Talving P, et al. Hyperfibrinolysis elicited via thromboelastography pre- dicts mortality in trauma. J Am Coll Surg 2012;215:496-502.

24. Hunt H, Stanworth S, Curry N, Woolley T, Cooper C, Ukoumunne O, et al. Thromboelastography (TEG) and rotational thromboelastometry (ROTEM) for trauma induced coagulopathy in adult trauma patients with bleeding. Cochrane Database Syst Rev 2015;(2):CD010438.

25. Rugeri L, Levrat A, David JS, Delecroix E, Floccard B, Gros A, et al. Diagnosis of early coagulation abnormalities in trauma patients by rotation thrombelastography. J Thromb Haemost 2007;5:289-95.

26. Kashuk JL, Moore EE, Wohlauer M, Johnson JL, Pezold M, Lawrence J, et al. Initial experiences with point-of-care rapid thrombelastography for management of life-threatening postinjury coagulopathy. Transfusion 2012;52:23-33.

27. Gonzalez E, Moore EE, Moore HB, Chapman MP, Chin TL, Ghasabyan A, et al. Goal-directed hemostatic resuscitation of trauma-induced coagulopathy: a pragmatic randomized clinical trial comparing a viscoelastic assay to conventional coagulation assays. Ann Surg 2016;263:1051-9.

28. Veigas PV, Callum J, Rizoli S, Nascimento B, da Luz LT. A systematic review on the rotational thrombelastometry (ROTEM $\left.{ }^{\circledR}\right)$ values for the diagnosis of coagulopathy, prediction and guidance of blood transfusion and prediction of mortality in trauma patients. Scand J Trauma Resusc Emerg Med 2016;24:114.

29. Prat NJ, Meyer AD, Ingalls NK, Trichereau J, DuBose JJ, Cap AP. Rotational thromboelastometry significantly optimizes transfusion practices for damage control resuscitation in combat casualties. J Trauma Acute Care Surg 2017;83:373-80. 